\title{
Da paralisia do cotidiano: abrindo espaços de saúde a partir do reconhecimento da doença
}

\author{
Guilherme Aguliari da Silva ${ }^{a}$, Francine Baltazar Assad ${ }^{a}$, Taís Quevedo Marcolino ${ }^{\mathrm{b}}$ \\ ${ }^{a}$ Universidade Federal de São Carlos - UFSCar, São Carlos, SP, Brasil. \\ 'Departamento de Terapia Ocupacional, Universidade Federal de São Carlos - UFSCar, São Carlos, SP, Brasil.
}

\begin{abstract}
Resumo: Este trabalho parte da ideia de que o sujeito-alvo da terapia ocupacional é aquele com dificuldades em seu cotidiano por razões diversas e variadas. $\mathrm{O}$ adoecimento pode ser uma das razões que influenciam a vivência de um cotidiano restrito ou com atividades relacionadas apenas ao tratamento, decorrentes da perda de domínio de si, no mundo, pela nova situação instaurada. Este artigo pretende apresentar um caso clínico de uma jovem com hipótese diagnóstica de transtorno afetivo bipolar e discutir o quanto o não reconhecimento e a não familiaridade com o novo contorno, advindo pelo adoecimento, abrem espaço para o cuidado em terapia ocupacional. Além disso, busca-se elucidar elementos do raciocínio clínico e dos procedimentos utilizados por um estagiário de terapia ocupacional em saúde mental, para conduzir esse processo terapêutico. As reflexões deste trabalho sustentam-se no Método Terapia Ocupacional Dinâmica (MTOD), que propõe ampliar espaços de saúde para o sujeito-alvo, de modo a construir/ampliar seu cotidiano, a partir do seu núcleo central, que é a dinâmica da relação triádica (terapeuta ocupacional, sujeito e atividades). Este relato de experiência é constituído pelo diagnóstico situacional do caso, pelo desenvolvimento do processo terapêutico e pelas reflexões e análises que o caso suscitou durante o estágio profissional em terapia ocupacional em saúde mental.
\end{abstract}

Palavras-chave: Terapia Ocupacional/Métodos, Terapia Ocupacional/Terapêutica, Saúde Mental, Transtornos Mentais, Conhecimentos, Atitudes e Práticas em Saúde.

\section{From the paralysis of everyday life: openning health spaces from the recognition of symptoms}

\begin{abstract}
We start from the idea that occupational therapy client/patient struggles to run their daily life for many and varied reasons. Illness may be one of many different reasons leading subjects to experience restriction in daily activities or a daily routine merely related to the treatment, resulting from the loss of self-control in the world brought about by the new established situation. This paper presents a clinical case of a young woman with a diagnostic hypothesis of bipolar affective disorder and discusses how the non-recognition and unfamiliarity with the new contour arising from the illness open space for occupational therapy care. Moreover, we try to elucidate elements of clinical reasoning and procedures used by a student of occupational therapy during his fieldwork education on mental health. Our reflections are based on the Occupational Therapy Dynamics Method (OTDM) whose proposal is to extend health spaces into the client/patient's life so as to build/expand their daily life activities, based on the analysis of the triadic relationship dynamic (occupational therapist, subject and activities). This experience report is composed by the situational diagnosis of the case, the development of the therapeutic process and the reflections and analysis that the case raised during the fieldwork experience in occupational therapy in mental health.
\end{abstract}

Keywords: Occupational Therapy/Method, Occupational Therapy/Therapeutics, Mental Health, Mental Disorders, Health Knowledge, Attitudes, Practice.

Autor para correspondência: Taís Quevedo Marcolino, Universidade Federal de São Carlos, Rodovia Washington Luís, Km 235, CEP 13565-905, São Carlos, SP, Brasil, e-mail: taisquevedo@gmail.com

Recebido em Nov. 17, 2015; 1ª Revisão em Maio 9, 2016; Aceito em Jul. 6, 2016. 


\section{Introdução}

Partimos da ideia de que o sujeito-alvo da terapia ocupacional é aquele que vivencia situaçóes que levam à perda de domínio sobre si no mundo e a consequente impossibilidade de projetar o futuro e se projetar nele (KUJAWSKI, 1991; FERRY, 2010), situando-o em uma posição de exclusão que o paralisa em seu cotidiano (BENETTON, 2006, 2010).

O cotidiano abarca o indivíduo no plano de sua vida em comum com os outros, assim como as expectativas que se criam na relação das pessoas umas com as outras e com as coisas, funcionando “[...] como uma gramática comunitária irrecusável que temos que preencher com nossa criatividade pessoal" (KUJAWSKI, 1991, p. 35).

Quando o cotidiano entra em crise, perde-se a familiaridade com o que está à volta, gerando dificuldades para o reconhecimento de si próprio nesse novo contexto, além de mal-estar e tensão por poder ser bruscamente afetado pelo que cotidianamente nos cerca (KUJAWSKI, 1991).

A doença pode ser uma das diversas razóes que influenciam o sujeito a vivenciar um cotidiano restrito ou com atividades relacionadas apenas ao tratamento (TAKATORI, 2001), decorrentes da nova situação instaurada. Especificamente, no campo da saúde mental:

[...] é nesse cenário de perda de domínio sobre sua vida, sobre suas atividades; de não mais se reconhecer como antes; do estranhamento do que antes lhe era familiar; da nomeação da doença como anteparo para o estabelecimento das relaçóes interpessoais dentro de uma cultura biomédica, que o afasta da construção de sentidos sobre o que lhe aconteceu; da inquietação pela impossibilidade de uma tranquilidade pela constante ameaça ora do mundo interno, ora do externo; da inexistência frequente do desejo, que somos chamados a vislumbrar possibilidades de mudança para essa realidade pessoal e social (MARCOLINO, 2016, p. 111).

Desse modo, o paradigma do tratamento da doença, essencial para a prática médica, instaura com a terapia ocupacional uma tensão constante, na medida em que o valor social da ausência de doença é maior do que o de que se pode viver mesmo com a doença, central ao paradigma da terapia ocupacional (BENETTON, 2005, 2010; MATTINGLY; FLEMING, 1994).

Este relato de experiência pretende, à luz da discussão de um caso clínico de uma jovem com hipótese diagnóstica de transtorno afetivo bipolar (TAB), apresentar o impacto no cotidiano com o advento de um transtorno mental, bem como discutir como, em um primeiro momento, o conhecimento sobre a doença pode ser uma estratégia para o reconhecimento do novo contorno, oferecendo à doença um lugar real na vida do sujeito, em suas relações com o social.

Nossas reflexôes sustentam-se no Método Terapia Ocupacional Dinâmica (MTOD), que propóe ampliar espaços de saúde para o sujeito-alvo, de modo a construir/ampliar seu cotidiano (BENETTON, 2010). Seu núcleo central é a dinâmica da relação triádica (terapeuta ocupacional, sujeito-alvo e atividades) e todos os procedimentos da (o) terapeuta ocupacional, que levam em conta os movimentos de ação e reação que são determinantes dessa dinâmica particular de funcionamento (BENETTON; MARCOLINO, 2013).

O diagnóstico no MTOD é situacional, ao descrever particularidades relativas ao sujeito na situação atual de vida, no início e no decorrer do processo terapêutico, e as informaçóes obtidas pela(o) terapeuta ocupacional a partir do que o sujeito fala de si e de suas atividades, o que ele faz no setting, e o que as pessoas de seu convívio pensam dele (BENETTON, 2006).

Nessa direção, o objetivo da terapia ocupacional diferencia-se do cuidado médico-clínico de cura/controle dos sintomas para fortalecer o autoconhecimento e melhores formas de realizar atividades cotidianas (BENETTON, 2005, 2010; BENETTON; MARCOLINO, 2013). O sintoma é compreendido como constituinte do sujeito e visto sempre em relaçáo às possibilidades de ampliação de atividades para construçóes no cotidiano. Mesmo atividades de cuidado da doença e/ou dos sintomas podem ser vislumbradas à luz da ampliação de espaços saudáveis (MAXIMINO et al., 2012).

\section{Método}

Trata-se de um relato de experiência, constituído pelo diagnóstico situacional do caso, pelo desenvolvimento do processo terapêutico e pelas reflexóes e análises que o caso suscitou. $\mathrm{O}$ caso relatado foi acompanhado durante o primeiro semestre de 2014, em atendimentos semanais, individual e grupal, em estágio profissional em terapia ocupacional em saúde mental, em uma clínica-escola.

Como se trata de uma instituição de ensino, assistência em saúde e pesquisa, todos os usuários desse serviço assinam um Termo de Compromisso 
Livre e Esclarecido, aceitando sua participação, direta ou indireta, em estudos, pesquisas e divulgação científica. Todos os nomes utilizados neste texto são fictícios.

\section{Relato da Experiência}

\subsection{Diagnóstico situacional, composto na relação estagiário-supervisoras}

As informaçôes para a composição diagnóstica inicial foram coletadas nos atendimentos iniciais, com destaque para as impressóes do estagiário do primeiro atendimento, e em um atendimento com a mãe.

\subsubsection{O encaminhamento}

Michele é uma jovem que veio encaminhada do setor de Terapia Ocupacional em Saúde Mental Infantojuvenil para o de Saúde Mental do Adulto, com hipótese diagnóstica de TAB, atualmente sob remissáo sintomatológica, por completar 18 anos e apresentar demandas relacionadas ao mundo adulto, como o desejo de trabalho.

O TAB é um transtorno grave, crônico e recorrente, caracterizado por oscilaçôes de humor, e em que pensamento, emoçóes e comportamento alteram-se visivelmente entre episódios de euforia e depressão. Afeta cerca de 1,6\% da população e tem importante impacto na vida do paciente, podendo ocasionar prejuízos funcionais expressivos, comportamentos inadequados ou não aceitos socialmente, e problemas de relacionamento interpessoal (MIASSO et al., 2009).

\subsubsection{O primeiro atendimento, pelo relato do estagiário}

No primeiro atendimento, observei que Michele demonstrou vergonha, agitaçáo e ansiedade, visíveis em sua "risada nervosa" e sua postura de "encolhimento do corpo", a cada questionamento voltado para ela. Disse que não tinha mais contato com amigos, que náo saía mais de casa para passear e que só ficava dentro de casa com os pais, referindo gostar de fazer compras no supermercado com o pai e de roupas no centro da cidade com a mãe, além de ver filmes românticos e novelas; ouvir música e dançar em frente ao rádio da sala, e fazer algumas atividades artesanais.

Quando questionada sobre o motivo pelo qual estava sendo acompanhada, disse que uma psicóloga falou que iria ajudá-la a ser menos tímida. Disse-me, envergonhada e aparentemente confusa, que também era acompanhada pela médica psiquiatra do CAPS (Centro de Atenção Psicossocial), por ter um quadro psiquiátrico, o TAB. Ficou em silêncio, logo depois.

Percebi que Michele demorou a falar sobre isso, era visível seu nervosismo, por uma inquietude do corpo, enquanto conversávamos sobre esse assunto. Minha percepção é que ela se referia ao diagnóstico com grande pesar e tristeza. Depois do breve silêncio, ela disse concordar com o diagnóstico, devido às alteraçóes de humor exacerbadas, e complementou, porém, que não tinha muito conhecimento sobre esse quadro, não sabendo dizer o que exatamente lhe aconteceu.

Em seguida, falou que mesmo após o diagnóstico, deu continuidade à vida. Disse-lhe que há poucos minutos ela havia dito o contrário, que as atividades e pessoas em sua vida estavam limitadas à casa e aos pais. Perguntei se ela achava que ter esse problema estava relacionado a esse presente vazio de pessoas e espaços. Ela, porém, ficou em silêncio e pensativa, com uma postura em que seus ombros estavam caídos para frente e com as mãos sobre as pernas, mas, depois de alguns segundos, disse que o questionamento correspondia à realidade que estava vivendo.

Para compreender melhor sua história e como seus familiares estavam compreendendo o que havia acontecido com ela, disse-lhe que precisaria conversar com sua família.

\subsection{3 $\mathrm{O}$ advento da doença e as crises}

No atendimento com a máe, ela falou de suas angústias em relação ao diagnóstico da filha, das dúvidas sobre a capacidade da filha ingressar no mercado de trabalho, do medo de seu futuro quando seus mais morrerem e do medo de que alguém mexa com ela na rua ou então que ela tenha um novo surto psiquiátrico, sem a presença dos pais.

A mãe contou que, nos momentos de crise, que ocorreram entre 14 e 16 anos, Michele ficava durante muito tempo sentada no sofá, olhando para o chão. Quando recebia visita, se escondia no quarto e também que ficava muito tempo sem fazer nada, demonstrando perda de interesse em fazer as atividades do seu dia a dia. Além disso, contou-nos sobre alguns episódios em que a filha fantasiava estar grávida de um príncipe. Atualmente, relataram que a filha continua como sempre, bastante tímida e quieta, mas que antes vivenciava mais o dia a dia. A mãe reconheceu que ela e o marido adotaram uma postura superprotetora em relaçáo à filha, mas que estavam dispostos a mudar. 


\subsubsection{A escola}

De acordo com a própria Michele e a mãe, ela sempre teve ótimas notas e nunca teve problemas de aprendizagem, mas que, aproximadamente, desde seus 12 anos, já referia que não queria ir mais à escola, o que se concretizou nos momentos de crise, pela perda de interesse, pela dificuldade de concentração e pelo pensamento suicida. Apesar disso, conseguiu retomar às atividades escolares, ora fazendo-as em casa, ora na escola, finalizando assim o Ensino Médio.

\subsubsection{As amizades}

Para a mãe, Michele sempre foi tranquila e tímida, e, por isso, acredita que tinha poucas amizades. Tanto Michele como sua mãe falaram de Samanta como a amiga mais próxima, pois passavam as tardes na casa uma da outra. Após as crises, houve um distanciamento entre as duas. Ambas disseram que Samanta tentou entrar em contato com Michele, mas essa sempre dava alguma desculpa para náo retomar a amizade.

Michele dizia ter amizades remanescentes do período escolar, porém admitia que fazia muito tempo que náo as reencontrava. Percebemos que Michele se mostrava ambivalente em relação à aproximação dos amigos, inclusive de Samanta, ora se mostrando excessivamente confiante e empolgada para retomar as amizades, ora se apresentando triste, envergonhada, culpada e com falta de vontade ou de prazer, optando assim por deixá-las de lado e julgando que seria melhor criar novos laços.

\subsubsection{A relação com a irmã}

Michele mora com os pais e com sua única irmã mais velha, Fabiana, e parece admirá-la muito, sempre relatando situaçóes relacionadas a ela. Embora diga que sua relaçáo é boa com todos os seus familiares, fala que gostaria de conversar mais com a irmã. Em alguns momentos, Michele demonstra querer ser igual à Fabiana, fazer atividades como ela faz, como viajar, ter amizades, namorar e trabalhar, inclusive no mesmo emprego. Quando fala sobre isso, Michele parece se sentir inferior à irmã.

\subsubsection{O desejo para o futuro}

Michele não tem formação e experiência profissional, mas sempre demonstrou desejo de trabalhar, ter um emprego, e acreditava que ter o próprio dinheiro poderia ajudá-la a ser mais independente. Apesar disso, observávamos que Michele apresentava dificuldades para tomar decisóes e ter iniciativas em atividades na terapia ocupacional, como no processo de pintura de um vaso, relatado adiante. Acreditávamos que essas dificuldades poderiam atrapalhar a sua participação social e o desejo de se inserir no mundo do trabalho.

\subsubsection{A dinâmica da relação triádica}

Nos primeiros atendimentos, o estagiário manteve uma postura investigativa e questionadora, que levou Michele a se sentir acuada e mais tímida. Ao modificar esse modo de se colocar na relação, estando mais relaxado e atento a atitudes, gestos e açóes de Michele, sem se preocupar tanto com o que ela dizia ou respondia, ela foi se mostrando mais disposta a falar sobre si e sua vida, trazendo espontaneamente diversos assuntos presentes no seu dia a dia e mostrando-se extremamente disponível para fazer atividades e refletir sobre elas.

\subsubsection{Nossa hipótese inicial}

Ao longo dos atendimentos, foi possível compreender que o repertório de amizades de Michele sempre foi restrito, que ela era uma garota mais introspectiva e tímida, mas que realizava suas atividades com autonomia e bom desempenho. Com o advento da crise, ela e sua família se fecharam no universo desconhecido da doença.

Além disso, a história sobre o adoecimento de Michele não estava tão clara, pois os sintomas descritos pela família não nos pareciam se ajustar ao $\mathrm{TAB}$, o que trazia dificuldades para compreender o que, de fato, havia ocorrido. Assim, esse foi um primeiro objetivo do atendimento em terapia ocupacional, abordar a doença com Michele, para que pudéssemos compreender a história, o contexto de seu desenvolvimento, e quais sentidos ela havia atribuído ao que lhe aconteceu.

Percebíamos que Michele sentia vergonha por ter uma doença psiquiátrica e pelos comportamentos que teve na crise, embora não soubéssemos exatamente como ela compreendia o que lhe aconteceu, além de ela ter medo de que tudo voltasse a acontecer. Esse novo universo parecia se colocar como um grande obstáculo, não somente para Michele, mas também para sua família, paralisando-os diante desse novo contorno, ainda desconhecido.

Entretanto, Michele não nos parecia uma garota sem desejos de seguir em frente, pois falava de projetos, espelhava-se na irmã, parecia querer encontrar algo dentro dela que lhe desse força para fazer o que 
gostaria de fazer, mesmo que de forma estereotipada, com toda a empolgação de que iria rever amigos, revivendo lembranças do passado escolar, no qual dizia que seu isolamento social não existia.

Outro ponto importante foi reconhecer a abertura da família para rever suas atitudes em relação à Michele e trabalhar conjuntamente conosco.

\subsection{Processo terapêutico à luz dos pressupostos do MTOD}

É no processo de realização de atividades com o terapeuta ocupacional que o sujeito-alvo começará a significar suas experiências, compondo um espaço de historicidade e de construção de um cotidiano saudável (a seu modo), e potencializando participação/ inserção social, objetivo final da intervenção em terapia ocupacional (BENETTON, 2010).

Uma vez que a própria vida cotidiana está imbricada no social, como construção pessoal na prática social, a terapia ocupacional no MTOD propóe-se a ser um espaço de encontro-construção para provocar transformaçóes (BENETTON, 2010). Nesse sentido, a função terapêutica se sustenta na ação educativa que, através de aprender, ensinar e realizar atividades, possibilita o reconhecimento do que pertence ao sujeito-alvo, de suas capacidades, habilidades e dificuldades reais, abrindo espaço para o desejo de fazer atividades, que possam ser ampliadas para o cotidiano (BENETTON, 2010; BENETTON; MARCOLINO, 2013).

Com essa estrutura para a construção do raciocínio clínico, em um processo de ensino e aprendizagem da prática, e com a composição diagnóstica inicial, foi possível traçar um projeto para Michele, que vislumbrasse uma mudança de postura dela diante das atividades que desejava fazer em sua vida e que também pudesse diminuir o "tamanho" da doença desconhecida, em seu cotidiano. Vale ressaltar que esse foi um projeto desenvolvido pelo o estagiário em questão. Como há trocas semestrais de estagiários, o diagnóstico situacional e a construção de projetos terapêuticos sáo constantemente elaborados, o que consideramos um fato interessante, dada a atualização das necessidades das pessoas sob nosso cuidado.

\subsubsection{Detalhes do processo, pelo estagiário}

No atendimento no qual Michele havia iniciado a atividade de pintura de um vaso, apontei que ela havia adotado uma postura muito passiva, sempre esperando que eu fizesse as escolhas para a realização da atividade e que eu indicasse os passos a serem seguidos.

Embora ela não tenha dito nada naquele momento, esse foi o início de uma maneira nossa de funcionar, de colocar a relação triádica em movimento. No atendimento posterior, foi possível ver uma mudança da postura dela em relação à atividade, ficando mais independente e espontânea. Além disso, disse-lhe que percebia que ela não estava atenta aos detalhes que poderiam deixar seu produto final mais interessante. Perguntei-lhe se essa postura não poderia estar presente em outras atividades do seu dia a dia, buscando abrir um espaço para ela pensar sobre o que faz e como faz as atividades na vida.

Michele sempre se mostrou aberta para as minhas colocaçôes. Na maioria das vezes, não construía um diálogo no aqui-e-agora do atendimento, porém comecei a observar que ela refletia sobre todas as colocações fora do atendimento e, em atendimentos posteriores, experimentava uma nova maneira de estar comigo e de realizar as atividades.

Diante da nossa hipótese de que o desconhecimento sobre a doença mantinha a ruptura causada pelo que lhe aconteceu, levei-lhe algumas informaçóes sobre o TAB.

Esse encontro foi o "divisor de águas" desse processo, pois Michele conseguiu se identificar com diversos sintomas do transtorno e conseguimos refletir acerca de quais açóes poderiam ser tomadas para que os episódios fossem menos frequentes. Era possível perceber que ela se sentia muito triste a cada sintoma que identificava e muito envergonhada, quando solicitado que ela relatasse alguma experiência relacionada ao sintoma. Acreditamos que o modo com que se dedicou a essa atividade, ajudou-a a falar da doença e a relacioná-la a eventos de sua vida, dos quais demonstrava vergonha e tristeza. Ao final do atendimento, percebi-a mais fortalecida, com algum senso de controle, que havia lhe sido tirado.

Após isso, propus um encontro em conjunto com a mãe para que as duas pudessem levantar alguns problemas que o advento da doença, a relação superprotetora da família e a postura acomodada de Michele haviam causado. Elas relataram que a falta de iniciativa para realizar as atividades que precisava ou desejava, a dificuldade de aceitar sugestóes - deixando as pessoas da família em um jogo de querer estimulá-la, ela rejeitando, e eles ficando sem energia para continuar a ajudá-la -, e suas reaçóes, ao ter seus desejos contrariados, foram algumas coisas que poderiam ser trabalhadas.

Durante os atendimentos, foi possível observar que Michele conseguiu se colocar em ação de um 
modo diferente, fazendo escolhas, justificando-as, e assumindo para si o controle do que queria e podia fazer, arriscando-se um pouco mais.

Nessa experimentação, ajudei-a a perceber-se proativa, dando feedback para suas conquistas. Avaliávamos conjuntamente como estavam suas atividades no cotidiano. Ela passou a vir mais bem arrumada; vir sozinha de ônibus; retomou o contato, via SMS, com algumas amigas; começou a sair sozinha para o centro da cidade, para comprar suas coisas; iniciou sua participação em um grupo de terapia ocupacional com outros jovens de sua idade; buscou informaçôes sobre cursos profissionalizantes; entregou currículos em busca de um emprego; começou a fazer atividades artesanais em uma escola próxima à sua casa; as brigas com seus pais passaram a ser menos frequentes, o que favoreceu uma maior aproximação e a realização de atividades com eles e com a própria irmã.

Em todo esse processo, trabalhamos fortemente: sujeito de desejos e açóes $\times$ sujeito preso/paralisado frente ao desconhecimento da doença. Busquei oferecer à Michele inúmeras reflexôes, mostrando sua postura passiva. Também, com o decorrer dos atendimentos, vimos uma jovem experimentando uma nova forma de ser, fazer e se relacionar.

\subsubsection{A avaliação do processo terapêutico pelas Trilhas Associativas}

$\mathrm{Na}$ medida em que a(o) terapeuta ocupacional observa, coleta informaçóes, fica atento a possíveis associações durante o e no fazer atividades, ele está funcionando dentro de uma relação que possibilita a construção de uma história, que favorece o encadeamento de ideias ou realizaçôes até entáo despercebidas pelo sujeito, para que ele possa nomear e reconhecer aquisições, habilidades, construções e autoconhecimento, enriquecendo com isso a sua vida cotidiana (BENETTON, 2010).

As trilhas associativas se constituem como uma técnica de análise de atividades pós-realização, com a participação ativa do paciente no processo de agrupamento, comparação, associaçáo e análise das atividades, permitindo, assim, preferencialmente, a construção de uma narrativa através do que foi feito. Possibilita a construção de um espaço subjetivo de historicidade, que conte não apenas a história do paciente fora do setting como também a própria história da relação construída durante o processo de terapia ocupacional (BENETTON, 2005).
Todo esse processo de enriquecimento da sua vida cotidiana pôde ser refletido em conjunto com Michele no processo de trilhas associativas, avaliando todas as atividades realizadas até então.

Michele não apresentou dificuldades quando foi solicitada para que separasse as atividades em grupos, pois rapidamente colocou as atividades fáceis de fazer no grupo "Fácil"; as atividades que estimularam sua imaginação e ajudaram entender seu diagnóstico, como o roteiro sobre o transtorno afetivo bipolar, no grupo "Boas e Legais"; as atividades que lhe causaram dor e tristeza, como quando teve que elencar os sintomas que já havia vivenciado e quando não conseguiu identificar como os sintomas estavam interferindo no seu cotidiano, dentro do grupo nomeado como "Difícil".

Em um segundo momento, após ter tido permissão da Michele para modificar os grupos, o estagiário manteve as atividades dentro do grupo "Fácil", mas complementou que foram atividades fáceis pelo constante auxílio do estagiário diante da passividade dela. Criou-se um novo grupo nomeado de "Divisor de Águas", o qual foi preenchido pelo atendimento individual com a mãe, pois foi, a partir desse momento, que os pais deram espaços para que Michele pudesse se "libertar"; também teve lugar nesse grupo o roteiro sobre o transtorno afetivo bipolar, que a ajudou a se conhecer melhor e a perceber que existe uma doença, porém esta não precisa impedir uma vida de qualidade. Além disso, o estagiário apontou que, a partir desse momento, a bolha na qual Michele estava presa explodiu-se e, desde então, ela vem se apresentando com mais autoestima, iniciativa, autonomia, independência e participação social.

Não houve nenhuma modificação no grupo nomeado como "Difícil", porém o estagiário ressaltou que, apesar das dores que essas atividades proporcionaram, foram também atividades muito importantes para que ela pudesse vivenciar a mudança de postura citada anteriormente.

Michele optou por não modificar a nova distribuição dos grupos, pois argumentou que, daquele jeito, estava melhor e que concordava com os apontamentos feitos. Além disso, Michele relatou que não havia percebido toda essa mudança, mas que, após esse processo de trilhas, conseguiu perceber que realmente estava diferente. Disse que antes ficava o dia inteiro em casa sem fazer nada, mas que hoje é diferente, pois realiza e frequenta outros espaços e atividades. Enquanto Michele falava, foi possível observar que seus olhos, sua boca e seu corpo estavam sorrindo, leves e contentes com essa evolução. 


\section{Discussão}

A doença, discutida aqui à luz de um transtorno mental, traz contingências para a vida das pessoas, levando-as a vivenciar boa parte de seu cotidiano com atividades ligadas ao seu cuidado (TAKATORI, 2001). Além disso, o impacto social do advento de uma doença ou deficiência coloca a pessoa - e aqueles que convivem com ela - diante de concepçóes/representaçóes sociais de doença/deficiência que demandam uma implícita tomada de decisão sobre como agir, seja pelo isolamento social, pela negaçáo, pela paralisação ou pelo enfrentamento. $\mathrm{Na}$ maioria das vezes, há uma paralisaçáo do movimento da vida, o que impossibilita novas criaçôes de saúde (LIMA, 2006).

Assim, a atitude assumida pela família de Michele é comum diante das dificuldades enfrentadas. Familiares de pessoas portadoras de transtornos mentais não sabem como lidar com as situações de crise e emergem, então, conflitos familiares, culpa, pessimismo, por náo conseguirem ver saída para os problemas, bem como isolamento social, expectativas frustradas de cura e desconhecimento da doença (COLVERO et al., 2004).

No movimento entre o individual e o social, esse aspecto pareceu-nos ser o alvo fundamental de nossa intervenção. Assim, o cuidado junto à família se deu centrado no cotidiano, em uma análise das atividades que eram necessárias tanto para o desenvolvimento de Michele - lembrando que ela vivenciou a crise em saúde mental na adolescência e que boa parte do que foi trabalhado com ela também faz parte do próprio processo de amadurecimento - como para um relacionamento positivo na família, de modo afetivo e criativo.

Com o decorrer dos atendimentos, Michele se permitiu experimentar uma nova forma de ser e de fazer, que foi inaugurada quando conseguiu encarar/enfrentar o que lhe havia acontecido, encarando os sintomas da doença e refletindo sobre as experiências que viveu quando estava em crise, tomando posse dessa história. Foi um processo difícil e doloroso, que permitiu que Michele se conhecesse melhor, que reconhecesse algo que é constituinte de sua vida, abrindo espaços saudáveis (de saúde mental), para superar sua paralisia diante do que havia lhe acontecido. Pois, como diz Solomon (2013, p. 26), tratar a identidade da pessoa como a doença "[...] convida a verdadeira doença a assumir uma postura mais corajosa”.

Cabe ressaltar que nossa questáo não foi a do convencimento da existência de uma doença ou a tentativa de encaixar vivências pessoais em sintomas.
Ao contrário, acreditamos que é necessário construir possibilidades para que o próprio sujeito denomine sua experiência como entender ou desejar, fomentando a ideia de posse desse sentido construído em sua vida cotidiana.

De acordo com Lima (2006, p. 121), estamos tratando de uma prática ligada à ideia de uma vida qualificada e particularizada, na qual

[...] o fato biológico náo pode ser pensado em separado do dado cultural, histórico, econômico, político. Vida que, em sua multiplicidade, não pode ser tomada em separado dos infinitos modos de vida.

Ao favorecer para que o sujeito adquira algum domínio sobre a doença (mesmo que seja o do conhecimento possível), a(o) terapeuta ocupacional pode trabalhar para abrir espaços para que a saúde mental do sujeito seja acionada para pensar e conseguir experimentar, e realizar atividades que favoreçam seu cotidiano, para ele, assim, viver a vida e não a doença.

\section{Conclusão}

Neste relato de experiência, sustentado pelo MTOD, buscamos destacar aspectos de um processo terapêutico elucidando procedimentos que favorecem a composição diagnóstica em terapia ocupacional, pelo diagnóstico situacional em sua análise qualitativa de todos os contextos relevantes para o sujeito-alvo; e procedimentos relacionais e educacionais que, na dinâmica de uma relação triádica, foram compondo um caminho favorecedor do auto conhecimento, como projeto para fazer e tomar posse de atividades no cotidiano.

A doença e seus cuidados são componentes do cotidiano e instauram relações importantes com o social. Neste relato, as atividades relacionadas ao conhecimento da doença e seu impacto nas relaçóes familiares e nas atividades (restritas) foram as que mais estiveram presentes. Pensar em inserçáo e participação social pela ampliação do cotidiano, implica em intervençôes centradas não somente no sujeito, mas também com as pessoas que participam desse cotidiano e que precisam reconhecer o sujeito em seu modo de ser, fazer e se relacionar.

Além disso, buscamos demonstrar como, pela técnica trilhas associativas, foi possível avaliar o processo vivido e favorecer com que o sujeito-alvo pudesse construir novos sentidos a partir da análise das atividades realizadas com a(o) terapeuta ocupacional. 
Esperamos que este trabalho possa ampliar a discussão sobre o arcabouço diagnóstico e procedimental em terapia ocupacional, oferecer-se como evidência clínica das possibilidades de estruturação do raciocínio clínico sustentado pelo MTOD, inclusive como experimentação na formação inicial (como é nosso caso), e apresentar-se como disparador de processos críticos e reflexivos sobre as possibilidades de prática em terapia ocupacional.

\section{Agradecimentos}

Agradecemos à Michele, pela autorização para a publicação deste relato. Na época, ao ler o manuscrito conosco, quase um ano depois, ela nos contou que estava até melhor do que o descrito no texto. Atualmente, pediu alta da terapia ocupacional e vem sendo acompanhada em atividades integradas de terapia ocupacional, psicologia e medicina em saúde mental, na mesma clínica-escola, o que vem nos possibilitando um cuidado mais integrado compara ela e sua família.

\section{Referências}

BENETTON, M. J. Além da opiniáo: uma questão de investigação para a historicização da Terapia Ocupacional. Revista CETO, São Paulo, v. 9, n. 9, p. 4-8, 2005.

BENETTON, M. J. Trilhas associativas: ampliando subsídios metodológicos à clínica da terapia ocupacional. Campinas: Arte Brasil Editora, UNISALESIANO, Centro Universitário Católico Auxilium, 2006.

BENETTON, M. J. O encontro do sentido de cotidiano na Terapia Ocupacional para a construção de significados. Revista CETO, São Paulo, v. 12, n. 12, p. 32-39, 2010.

BENETTON, M. J.; MARCOLINO, T. Q. As atividades no Método Terapia Ocupacional Dinâmica. Cadernos de Terapia Ocupacional da UFSCar, São Carlos, v. 21, n. 3, p. 645-652, 2013.
COlVERO, L. A.; IDE, C. A. C.; ROLIM, M. A. Família e doença mental: a difícil convivência com a diferença. Revista da Escola de Enfermagem da USP, São Paulo, v. 38, n. 2, p. 197-205, 2004.

FERRY, L. Aprender a viver: filosofia para os novos tempos. Rio de Janeiro: Objetiva, 2010.

KUJAWSKI, G. M. A crise do cotidiano. In: KUJAWSKI, G. M. A crise do século XX. São Paulo: Editora Ática, 1991. p. 31-61.

LIMA, E. M. F. A. A saúde mental nos caminhos da terapia ocupacional. Mundo Saúde, São Paulo, v. 30, n. 1, p. 117-122, 2006.

MARCOLINO, T. Q. Como trabalhamos com a noção de ampliação de cotidiano: consideraçôes a partir do Método Terapia Ocupacional Dinâmica. In: SALLES, M. M.; MATSUKURA, T. S. (Ed.). Cotidiano, atividade humana e ocupação: perspectivas da Terapia Ocupacional no campo da saúde mental. São Carlos: EDUFSCar/ FAPESP, 2016.

MATTINGLY, C.; FLEMING, M. H. Clinical reasoning: forms of inquiry in a therapeutic process. Philadelphia: F. A. Davis Company, 1994.

MAXIMINO, V. S.; PETRI, E. C.; CARVALHO, A. O. C. A compreensão de saúde para o Método Terapia Ocupacional Dinâmica. Revista CETO, São Paulo, v. 13, n. 13, p. 34-40, 2012.

MIASSO, A. I.; MONTESCHI, M.; GIACCHERO, K. G. Transtorno Afetivo Bipolar e adesáo ao medicamento e satisfaçáo com o tratamento e orientação da equipe de saúde de um núcleo de saúde mental. Revista Latino-Americana de Enfermagem, Ribeirão Preto, v. 17, n. 4, p. 548-566, 2009. http://dx.doi.org/10.1590/ S0104-11692009000400018.

SOLOMON, A. Longe da árvore: pais, filhos e a busca da identidade. São Paulo: Companhia das Letras, 2013.

TAKATORI, M. A terapia ocupacional no processo de reabilitação: construção do cotidiano. Mundo Saúde, São Paulo, v. 25, n. 4, p. 371-377, 2001.

\section{Contribuição dos Autores}

Guilherme Aguliari da Silva e Francine Baltazar Assad participaram da elaboração, redação e discussão do texto. Taís Quevedo Marcolino participou da revisão conceitual, discussão e redação final do texto. Todos os autores aprovaram a versão final do texto. 